\title{
Contextual Predictors of Self-Determined Actions in Students with and without Intellectual Disability
}

Cristina Mumbardó-Adam ${ }^{1}$, Karrie A. Shogren ${ }^{2}$, Joan Guàrdia-Olmos ${ }^{3}$, Climent Giné ${ }^{1}$

${ }^{1}$ Facultat de Psicologia, Ciències de l'Educació i de l'Esport Blanquerna. Universitat Ramon Llull

${ }^{2}$ University of Kansas. Kansas University Center on Developmental Disabilities

${ }^{3}$ Facultat de Psicologia. Institut de Neurociències. Universitat de Barcelona.

\section{Acknowledgments}

The author wishes to thank David Simó-Pinatella for his comments on drafts of this article.

\section{Funding}

This work was supported by SUR of the DEC of Generalitat de Catalunya for the predoctoral fellowship [2016FI_B00253] and by Social European Founds. The author guarantees that no financial interest or benefit arises from the direct applications of this research.

Contact author:

Cristina Mumbardó Adam

Facultat de Psicologia, Ciències de l'Educació i de l'Esport Blanquerna.

Universitat Ramon Llull

Cister, 34

08022 Barcelona, Spain

Cellphone: 645532394

Email: cristinama6@blanquerna.url.edu 


\begin{abstract}
Evidence in the field of intellectual disability supports the positive transition outcomes that the promotion of self-determination triggers for youth with disabilities. This article examines the contributions of contextual and personal variables to in predicting both students with and without disabilities self-determined actions. The Spanish pilot versions of the SelfDetermination Inventory and the AIR Self-Determination Scale were administered to 114 youth with and without disabilities. Contextual and personal variables were treated as predictor variables for analytic purposes. The results indicate the relevance of contextual variables in predicting both self-reported capacities and the essential characteristics of selfdetermination. Particularly, opportunities given at school and at home to engage in selfdetermined actions played a significant role. The practical implications of these findings and suggestions for future research are discussed.
\end{abstract}

Key Words: Self-determination, Contextual predictors, Self-Determination Inventory 


\section{Contextual Predictors of Self-Determined Actions in Students with and without}

\section{Intellectual Disability}

Students with intellectual disability can experience challenges during the period of transition from secondary to post-school life (e.g., from school to work, postsecondary education, and community living) as social and contextual demands gradually increase from classroom and family context requirements to job and citizenship demands (Morningstar, Lombardi, Fowler, \& Test, 2015; Wehman, 2006). These changing demands create a need for environmental supports embedded in the community and individualized supports provided across work and education settings (Shogren, Luckasson, \& Schalock, 2014). Teaching and supporting self-determination skills, such as choice making, self-management, goal setting and self-advocacy, can help students to face these contextual challenges when transitioning to adult life (Test, Mazzotti, Mustian, Fowler, Kortering, \& Kohler, 2009).

\section{Promoting Self-Determination for All Students}

There is evidence that promoting self-determination, defined as a "dispositional characteristic manifested as acting as the causal agent in one's life" (Shogren, Wehmeyer, Palmer, Forber-Pratt, Little, \& Lopez, 2015, p. 258), triggers more positive post-school transition outcomes for youth with and without disabilities (i.e., Shogren, Lopez, Wehmeyer, Little, \& Pressgrove, 2006). For example, researchers have found that self-determination status when exiting high school significantly predicts postschool community access $(\beta=$ $1.078 ; p<.000)$ and employment $(\beta=0.504 ; p=.019)$ (Shogren, Wehmeyer, Palmer, Rifenbark, \& Little, 2015). Fostering self-determination skills across the secondary education curriculum, providing students with supports to develop these skills, and offering a wide range of experiences and opportunities to exercise them can lead to enhanced selfdetermination. In this sense, Shogren et al (2015) found increases in standardized mean scores on measures of self-determination to almost $10 \%$ after intervention. Wehmeyer and 
colleagues (2012), in a study using the Self-Determined learning Model of Instruction (SDLMI; Mithaug, Wehmeyer, Agran, Martin, \& Palmer, 1998) found a moderate benefit (typical for educational interventions) for the treatment group (effect size increases .00 to .30), in a randomized control trial of the impact of the SDLMI when self-determination skills were taught longitudinally and embedded across academic and transition curriculum-based activities. Providing all students, including those without disabilities, with opportunities to develop self-determination has been acknowledged as important (Shogren, Wehmeyer, \& Lane, in press), as supporting the self-determination learning for students with intellectual disability in inclusive environments. Promoting self-determination with all students will create opportunities for them to benefit from universal and evidence-based educational instruction that results in greater outcomes, which aligns with the principles that are postulated by Multi-tiered Systems of Supports (MTSS) models. MTSS is an approach to organizing high quality academic and behavioral supports for all students, and utilizes a three-tiered model of supports based on student needs. Efforts have been made to emphasize college and career readiness skills in MTSS, which is naturally aligned with efforts to promote self-determination (Morningstar, Lombardi, Fowler, \& Test, 2015). The ultimate goal of MTSS implementation encompasses the promotion of social, behavioral and academic competences providing a framework to teach transition skills and foster greater personal outcomes. Knowing one's own strengths and weaknesses, setting accurate goals and self-regulating actions to reach those goals are just some examples of skills directly linked to self-determination that can benefit all students in MTSS frameworks (Shogren, Wehmeyer, Palmer, Forber-Pratt, Little, \& Lopez, 2015) as these skills can act as supports to navigate contextual demands and promote success in school and post-school contexts.

\section{Assessing Self-Determination for All Students}


Literature largely supports that students with disabilities benefit from selfdetermination interventions, for example showing mild (e.g., 10\% in Shogren et al., 2015) to moderate increases (e.g., .30 increased effect size in Wehmeyer et al., 2012) in the skills related to self-determination, though less is known about students without disabilities (Shogren, 2013). Further research is needed on the factors that influence self-determination skills across students with and without disabilities to enable researchers and practitioners to assess and understand those factors. Such information can inform the development of Tier 1 interventions to promote self-determination in MTSS frameworks. An assessment is under development, the Self-Determination Inventory: Student Report (SDI: SR; Shogren, Wehmeyer, Little, Forber-Pratt, Palmer, \& Seo, 2015), to enable the measurement and evaluation of the outcomes described above. The instrument, which is currently being validated with students with and without disabilities, gathers data on the three essential characteristics of self-determined actions that are defined within the Causal Agency Theory framework (Shogren, Wehmeyer, Palmer, Forber-Pratt, Little, \& Lopez, 2015): volitional action, agentic action, and action control beliefs. The volitional actions domain collects information on the degree to which students act with autonomy and self-initiation and choose goals based on preferences. The agentic actions domain includes self-regulation, selfdirection and pathways thinking and refers to "the ability to self-regulate, keep goals in mind to work toward completion, and monitor progress toward goal attainment" (Palmer, Wehmeyer \& Shogren, 2016; p. 16). Finally, action-control beliefs include control expectancy, psychological empowerment and self-realization and encompass one's selfknowledge of the capacities and the abilities that are used to reach a goal.

\section{Variables Influencing Self-Determination}

Researchers have begun to explore the contextual factors (i.e., personal and environmental factors) that impact self-determined actions; however, further research is 
needed. Promoting self-determination within an MTSS approach implies a focus on understanding environmental variables that influence self-determination (Shogren et al., 2014), such as opportunities to develop self-determination, while taking personal variables into account (i.e., age, gender, support needs). Few studies to date have comprehensively examined both personal and environmental factors that exert an influence across students with and without disabilities, leading to incomplete information on the influence of context in shaping self-determination in students with and without disabilities (Mumbardó-Adam et al., 2016). Provided opportunities both at school and at home support students with disabilities to engage in self-determined actions (Carter, Owens, Trainor, Sun, \& Swedeen, 2009; Mason, Field, Sawilowsky, 2004; Cavendish, 2016; Pierson, Carter, Lane, \& Glaeser, 2008), but have also not been found to be a significant predictor of self-determination skills (Shogren et al., 2007).

Personal variables such as gender, age and level of intellectual functioning do also play a significant role in students' self-reported self-determination (Shogren 2013), suggesting the importance of taking them into account when planning for instruction. For example, researchers have found that young women with disabilities in the U.S. are reportedly more self-determined (Lee et al., 2011; Shogren et al., 2007), though men without disabilities have also scored higher in terms of self-determination measures in other countries, such as Italy (Nota, Ferrari, Soresi, \& Wehmeyer, 2007). Other studies in other cultural contexts, such as Spain, have not found significant differences based on gender (Vicente, Verdugo, Gómez-Vela, Fernández-Pulido, Wehmeyer, \& Guillén, in press; Wehmeyer, \& Garner, 2003). With regards to age, self-determination skills tend to increase throughout adolescence (Nota, Soresi, Ferrari, \& Wehmeyer, 2011; Shogren, Wehmeyer, Palmer, \& Paek, 2013), though it has not been reported as a significant self-determination predictor (Vicente, Verdugo, Gómez-Vela, Fernández-Pulido, Wehmeyer, \& Guillén, in 
press). In terms of intellectual functioning, several studies have found that IQ is a predictor of self-determination (Carter et al., 2013; McGuire \& McDonnell, 2008; Shogren et al., 2007; Wehmeyer \& Garner, 2003), though IQ does not solely account for differences in selfdetermination levels (Mumbardó-Adam et al., 2016). As this body of research suggests, there is a need for further empirical work to address how those described variables impact the selfdetermination construct across students with and without disabilities to inform the development of frameworks for embedding self-determination interventions in MTSS models.

As such, this primarily descriptive study sought to answer two research questions. First, this study explored differences between students with and without intellectual disability enrolled in Spanish schools in terms of their self-reported capacities and opportunities for self-determination, and the self-reported levels of the three essential characteristics of selfdetermination (volitional action, agentic action, and action-control beliefs). We specifically focused on students with intellectual disability, compared to students without disabilities, because of the structure of the secondary education system in Spain, where this study was conducted. Second, this study sought to examine the personal and environmental variables that predict the three essential characteristics of self-determined actions and the students' self-reported capacities for self-determination. Answering these questions will allow us to broaden our understanding of self-determination development and expression across contexts and cultures by informing and enriching the existing body of literature through knowledge embedded in a specific cultural context (described below).

\section{Method}

\section{Participants}

Study participants were recruited across different geographical zones of Catalonia, a region of the north of Spain, targeting both rural and urban zones. Given that the target age of 
participants was 13-22, several schools and universities, each with a well-established longterm collaboration history with the research team, were invited to participate in the study. Specifically, we intentionally contacted fifteen general education schools and universities and special schools that primarily served students with intellectual disability spread throughout the geographical zones of Catalonia. From the 15 contacted, 12 general education schools, universities, and special schools agreed to participate in the study, 3 general education schools: 2 private general education schools and a college university, and 9 special education schools for students with intellectual disability. A sample of the questionnaires was sent to special education schools $(n=9)$, so as teachers could intentionally chose all the school students aged 13 to 22 years with intellectual disability who could provide reliable information when answering the questions (i.e., they should have enough language comprehension to understand the items if support was provided) and were willing to participate. Once potential participants were selected, consent (either from the parent or the participant if they were of legal age) was obtained. For student participants who were not of legal age, assent was also obtained. Each school provided about 6 students $(M=6.11 ; S=$ 2.03).

General education schools $(n=2)$ were asked to select a class between $9^{\text {th }}$ and $12^{\text {th }}$ grade, and the college university was asked to select a $1^{\text {st }}$ or $2^{\text {nd }}$ year class. Participating sites selected a 9th and 11th grade class, as well as a 1st year university class. Only those students with consent for participation were included. None of those classes in the general education schools had students with intellectual disability enrolled, which reflects the current status of educational placement in Catalonia of students with intellectual disability, where $42 \%$ of students with intellectual disability are still being taught in separate settings, (Ministerio de Educación, Cultura y Deporte, 2015). Therefore, promoting research to describe and better 
understand the Spanish school context is critical to inform current and future practices and policies to promote inclusive practices, a target of the Catalonia Ministry of Education.

In total, 114 middle school and high school youth in Spain participated in the study; $55(48.2 \%)$ were students with mild to moderate intellectual disability enrolled in special education schools and 59 (51.8\%) were students without disabilities enrolled in public and private general education schools or a university. On average, students were 17 years old ( $M$ $=17.36 ; S D=2.70)$, ranging from 13 to 22 , the majority being female $(66.7 \%)$. In terms of disability severity, $26(47.3 \%)$ students were reported as having mild intellectual disability and $26(47.3 \%)$ were classified as having a moderate intellectual disability. Additionally, 3 students (5.4\%) were diagnosed with Autism Spectrum Disorder. In terms of race/ethnicity, the majority of the sample was white/Caucasian (96.5\%), with $3.5 \%$ of the students being Hispanic.

\section{Procedures}

Students responded to two self-report surveys (described below) on their selfdetermination skills and capacities and opportunities to engage in self-determined actions. They were first asked to complete the Self-Determination Inventory System: Student Report (SDI-SR; Shogren, Wehmeyer, Little, Forber-Pratt, Palmer, \& Seo, 2015) followed by the AIR Self-Determination Scale (AIR; Wolman, Campeau, Dubois, Mithaug, \& Stolarski, 1994), and were provided as much time as needed to complete the scales. The first author was present during the questionnaires administration to support administration and clarify of items and response scales, consistent with scale administration protocols. If there were missing answers, the first author followed up with students to determine if they have inadvertently skipped questions, which was the case for all the detected missing answers $(n=$ 12), and were then asked to complete them; or if they have decided to leave items unanswered. For students with intellectual disability, supports included: (1) facilitating access 
to information (i, e. reading the questions), (2) understanding and interpreting questions (i.e., giving synonyms of misunderstood words), and (3) marking answers on paper in case of motor impairment. All the students with intellectual disability $(n=55)$ were provided with at least one type of support, depending on their needs.

\section{Instruments}

The Self-Determination Inventory System. The SDI-SR measures the essential characteristics of self-determination action, which are volitional actions, agentic actions and action-control beliefs (Shogren, Wehmeyer, Palmer, Forber-Pratt, Little, \& Lopez, 2015). The instrument operationalizes Causal Agency Theory, and builds on previous assessments such as The Arc's Self-Determination Scale (ARC-SD; Wehmeyer \& Kelchner, 1995), which operationalized the functional model of self-determination (Wehmeyer, 1992; Wehmeyer, Kelchner, \& Richards, 1996) to measure personal self-determination. The Spanish pilot version of the SDI-SR, which was translated and is being validated in Spanish populations, was used in this study. The SDI-SR Spanish version includes 51 items and is divided into the same three dimensions and eight sub-dimensions of the previously described original English version. To answer each item, students draw a mark on a line that simulates a ruler with tick marks that are subsequently used to calculate scores on a scale ranging from 0 ("I disagree") to 10 ("I agree"). The self-regulation subscale is however rated in a different way, as it comprises 6 items that represent 6 different situations, with a beginning and an end. The student is provided with 3 options to complete the middle of the situation, representing different ways to reach the end of the story given its beginning, and must match them to the following labels "best option", "next best option" and "worst option". The SDI-SR, which is currently being validated and normed in an American population of students with and without disabilities, has demonstrated acceptable model fit $\left(\chi^{2}(34)=63.861, \mathrm{RMSEA}=.075, \mathrm{CFI}=\right.$ $.976, \mathrm{TLI}=.960, \mathrm{SRMR}=.038)$ in adolescents with and without disabilities (Shogren, 
Wehmeyer, Little, Forber-Pratt, Palmer, \& Seo, 2015).

The AIR Self-Determination Scale. The AIR-S measures a person's capacities and opportunities for self-determination and is available in Student, Educator, and Parent versions. For the purpose of this study, the Spanish pilot version of the student form (AIR-S), which is currently being adapted and validated into Spanish populations for youth with and without disabilities, was used to measure students' capacity and opportunities for selfdetermination. The AIR-S has 24 questions that are divided in two scales that gather data on students' self-reported capacities and opportunities to engage in self-determined actions. The Capacity scale is further divided into two subscales and covers questions about student's (1) ability related to self-determination (Ability subscale) and (2) perceptions about performing self-determined actions (Perception subscale). The Opportunity scale is also composed of two subscales that measure (1) students' perceptions of their opportunities to perform selfdetermined actions at home (Opportunities at Home subscale) and (2) at school (Opportunities at School subscale). Scores are rated on a Likert scale from 1 (Never) to 5 (Always). The AIR has been extensively used in the field and has been shown to have adequate test-retest reliability (.74 after 3 months) and a strong internal consistency (split-half test $=.95$; Cronbach's alpha ranging from .89 to .99 ). In terms of validity, the original authors conducted a factor analysis that supported a four-factor structure explaining the $74 \%$ of the instrument variance (Mithaug, Mithaug, Agran, Martin, \& Wehmeyer, 2003).

\section{Data Analysis}

To answer our first research question, we tested for differences in the means of the four subscales of the AIR and the three subscales of the SDI-SR, using $t$-tests comparing students with and without intellectual disability. For the second research question, given the complexity of the models we wanted to analyze, since both the response variables and the predictors were measured in different metrics, General Linear Models were performed. The 
following variables were used as response variables: capacities, volitional actions, agentic actions and action-control beliefs. Personal variables including the presence of intellectual disability, gender and age, and environmental variables such as opportunities at home and at school were treated as predictors. For the purposes of this study the Capacity scale was used without differentially treating its two subscales as a response variable, whereas the two subscales of the Opportunity scale were used independently as predictors. Four models were then analyzed, one for each response variable, with the previously described environmental and personal variables as predictors.

First, composite scores were created to represent the four response variables as well as two predictor variables: students' opportunities at home and at school. Students rated the opportunities they were provided in both contexts to engage in self-determined actions on a scale of 1 to 5, with 1 being "Never" and 5 being "Always". Each student's responses were summed to form the Opportunities at School and Opportunities at Home composite score. For self-reported capacities and each of the three characteristics of self-determined actions, a) volitional actions, b) agentic actions, and c) action-control beliefs composite scores were created assuming all the items loadings to have the same weight. A linear model was assumed due to the newness of Causal Agency Theory and the lack of empirical knowledge. Then, Kolmogorov-Smirnov tests were performed to check the normality assumption of the data distribution. For all the response variables, and with at least one predictor variable, Kolmogorov-Smirnov test was statistically significant (e.g., for agentic action and gender, $p$ $=.004$ ), so models were performed assuming gamma distributions (Guàrdia-Olmos, Fuente, \& Lozano, 2008). Finally, logarithm links were used for the continuous response variables (volitional actions, agentic actions, and action-control beliefs) and power link at 0.05 for the ordinal response variable (capacities). Race/ethnicity was not added as a predictor variable, due to the low variability in the data (96.5\% white/Caucasian). All the analyses were 
performed using SPSS 22.0 version software with signification corrected for Bonferroni procedure.

\section{Results}

The first research question explored whether there were significant differences between students with and without intellectual disability in their capacities and opportunities for self-determined behaviors in their contexts and in the three essential characteristics of self-determination. Differences were found in students' self-reported capacities $(t(89.29)=-$ $2.022, p=.046)$, with students without disabilities scoring higher, and although Bonferroni correction does not yield statistical significance in this case, a significance tendency must be outlined. Similarly, students without disabilities reported more opportunities at home $(t(112)$ $=-2.082, p=.040)$ to develop self-determination. For opportunities given at school, significant differences were found $(t(112)=2.49, p=.014)$, but students with intellectual disability scored higher. Significant differences were found in essential characteristics of selfdetermined actions: volitional actions $(t(112)=-7.227, p<.001)$, agentic actions $(t(96.31)=$ -7.22, $p<.001)$, and action-control beliefs $(t(102.65)=-4.641, p<.001)$. In all domains, students without disabilities reported higher self-determination scores.

The second research question asked whether personal and environmental variables also play a significant role in predicting both the essential characteristics of self-determined actions and self-reported capacity for self-determination. Results are presented in Table 1 for the essential characteristics, but the most relevant findings are synthesized below. Regarding volitional actions $(M=68.215, S D=13.126)$, the model showed a good fit both by logarithm likelihood ratio estimate $(L L R=-404.595)$ and omnibus contrast $\left(\chi^{2}=104,362, d f=42, p<\right.$ $.001)$. Intellectual disability $(p<.001)$ and opportunities at home $(p=.015)$ significantly predicted volitional action. None of the other predictors were significantly associated with volitional actions. 
For agentic action $(M=49.546, S D=8.172)$, the model showed a good fit both by logarithm likelihood ratio estimate $(L L R=-361.47)$ and omnibus contrast $\left(\chi^{2}=89.322, d f=\right.$ $42, p<.001)$. Intellectual disability $(p<.001)$ and age $(p=.018)$ significantly predicted agentic action. None of the other predictors were significantly associated with agentic action.

In terms of action-control beliefs $(M=74.011, S D=11.709)$, the model showed good fit both by logarithm likelihood ratio estimate $(L L R=-382.707)$ and omnibus contrast $\left(\chi^{2}=\right.$ $128.883, d f=42, p<.001)$. Intellectual disability $(p<.001)$, age $(p=.007)$, opportunities at school $(p=.006)$ and opportunities at home $(p<.001)$ significantly predicted action-control beliefs. None of the other predictors were significantly associated with action-control beliefs. Insert Table 1 about here

Table 2 gathers the results for self-reported capacity for self-determination. Personal and environmental variables played a significant role in predicting students' self-reported capacities. The model showed a good fit for self-reported capacities $(M=23.75, S D=3.355)$, both by logarithm likelihood ratio estimate $(L L R=-233.943)$ and omnibus contrast $\left(\chi^{2}=\right.$ 136.020, $d f=42, p<.001)$. Age $(p=.001)$. Opportunities at school $(p<.001)$ and opportunities at home $(p<.001)$ significantly predicted students' self-reported capacities, whereas none of the other predictors were significantly associated with it.

Insert Table 2 about here

\section{Discussion}

\section{Summary of Findings}

The main aim of this study was to explore if personal and environmental factors acted as predictors of the essential characteristics of self-determination and student's self-reported capacities for self-determination. The results of the study confirm other research that suggests that students with intellectual disability tend to report lower scores on personal measures of self-determination (e.g., Shogren, Kennedy, Dowsett, Garnier-Villarreal, \& Little, 2012). 
Interestingly, the findings also suggest that students with intellectual disability, when compared to their peers without disabilities, report more opportunities to develop selfdetermination skills at school, but fewer opportunities at home in Spain. This suggests a differential emphasis on self-determination in special schools, identifying a need to consider ways to enhance the focus in regular schools, particularly as greater inclusion and the adoption of MTSS models are considered. Further research is also needed to explore if this holds across cultural contexts, and the degree to which self-determination is valued at higher levels in supports for students with intellectual and other disabilities.

Intellectual disability predicted each of three essential characteristics of selfdetermination. Volitional actions were also predicted by opportunities at home; agentic actions by age; and action-control beliefs by age, opportunities at school and at home. Finally, opportunities provided both at school and at home to develop self-determined skills, as well as age predicted student's self-reported capacities for self-determination. These findings confirm that self-determination develops as students' age (Nota, Soresi, Ferrari, \& Wehmeyer, 2011; Shogren, Wehmeyer, Palmer, \& Paek, 2013) and that students with intellectual disability tend to report lower levels of self-determination.

\section{Environmental Variables Predicting Self-Determination}

Previous studies (Carter, Owens, Trainor, Sun, \& Swedeen, 2009; Cavendish, 2016; Cavendish, 2016; Mason, Field, Sawilowsky, 2004; Pierson, Carter, Lane, \& Glaeser, 2008) have described opportunities for self-determination as significant predictors of selfdetermined actions, but none examined them along with factors in students with and without disabilities. The finding that essential characteristics of self-determination and self-reported capacities for self-determination are predicted either by opportunities at home or at school, or by both, suggests the critical importance of these opportunities. However, a unique finding of this study is that across students with and without disabilities it appears differential 
opportunities may be provided across home and school environments. Perhaps schools systems are placing greater focus on self-determination in the Spanish context for students with intellectual disability, aligned with research and practice strategies emerging in the field. However, less work has focused on family expectations and how self-determination can be supported in the home environment, perhaps reflecting the need for more focus on supporting families to promote self-determination (Palmer et al., 2003, 2016). Further research is needed to further explore this finding, and to consider ways to intervene with students with and without disabilities across home and school environments, with a particularly focus on integrated environments.

Further, while intellectual disability was found to have an impact on the three essential characteristics of self-determination, it was not a significant predictor of students' self-reported capacities. This highlights that the AIR Self-Determination Scale is measuring differing elements related to capacity and opportunities for self-determination that diverge from the essential characteristics of self-determination measured by the SDI-SR, consistent with previous research (Shogren et al., 2008). The SDI-SR provides information on the degree to which students endorse the three essential characteristics of self-determination. Because SDI-SR seems to display a snapshot of the students' self-determination abilities at a specific time, we could expect intellectual disability to be a predictor of these essential characteristics. Further research is needed, particularly across students with and without intellectual disability, to examine differences in the aspects of self-determination measured on the two scales, as well as to inform the use of the scales in educational planning and evaluation of interventions to support the development of self-determination in students with and without disabilities in inclusive settings.

\section{Limitations}

The previously presented findings do have some limitations that must be considered 
in interpreting the findings. First, the sample was intentionally recruited in Spain, so the results might be interpreted within the context where the sample was drawn. Second, the students with intellectual disability in our sample were not representative of the entire population of students with disabilities as they were enrolled in special education schools for students with intellectual disability. Therefore, the results of this study are limited to a comparative description of students with disabilities in a specific segregated context, compared to students without disabilities in general education contexts. However, this information is important as efforts are being made in Spain to consider ways to educate more students in the general education schools and classrooms, and informs issues to be considered with working to transfer instruction on self-determination to those environments. Our results preliminary describe the relevance of environmental factors in self-determination development, though this influence might substantially vary when dealing with students with disabilities enrolled in general education schools, necessitating future research. Third, only a small number of personal variables were assessed in this study, as race/ethnicity, for example, could not be analyzed due to the scarce sample variability. Fourth, data on students support needs could not be collected or analyzed, and schools could only provide students intellectual functioning. Further in the analyses, only the presence or absence of intellectual disability was considered, which narrows the interpretation.

\section{Implications for Research and Practice}

Despite these limitations, the findings provide direction for future research and practice. Causal agency theory (Shogren, Wehmeyer, Palmer, Forber-Pratt, Little, \& Lopez, 2015) provides practitioners and researchers with an updated framework to fully describe, understand, assess and develop strategies to teach self-determination skills to students with and without disabilities. However, the newness of this framework and of considering the role of self-determination as a Tier 1 intervention to promote access for all students to general 
education schools and curriculum necessitates future research. Clearly, in the Spanish context, emphasis has been placed on self-determination in segregated classrooms, but considering ways to incorporate this into the general education classroom and curriculum for all students as students with intellectual disability become part of those classrooms is needed. Work is also needed to understand opportunities provided at home and school for students with and without disabilities. Limited research has examined opportunities at home across students with and without disabilities, in any cultural context, suggesting the need for future research both on opportunities provided at home as well as on how to coordinate selfdetermination instruction and supports across home and school. Abilities linked to volitional actions, such as making autonomous choices, are traditionally taught and learned at school from early ages (Palmer, Wehmeyer, \& Shogren, 2016) in many contexts, particularly the Spanish context, and might be less impacted in adolescence and young adulthood by other personal factors, as found in this study. However, opportunities provided at home do influence volitional actions development, where students with disabilities reported to have fewer occasions to engage in self-determined actions when compared with their peers without disabilities. Family supports are needed to create opportunities for youths to develop volitional actions. Together with agentic actions, those skills will lay the foundations of action-control beliefs, which might be then endorsed in both home and school contexts (Palmer, Wehmeyer, \& Shogren, 2016).

Differing from other findings in Spanish context (Vicente et al., in press), where age has not been found to be a significant predictor of self-determination, our results find that students' age directly influences both the abilities to direct and regulate actions, and their beliefs about their abilities to reach their goals. Those skills might as well progressively develop as a result of the students' interaction with their challenging contexts (Palmer, Wehmeyer, \& Shogren, 2016) and need to be taught from early adolescence. Future research 
might go deeper in developing tailored interventions delivered in ways that benefit both younger and older students.

The findings suggest that both school and family context directly impact actioncontrol beliefs. Within these contexts, major efforts need to be done to strengthen and boost students' sense of personal empowerment (Shogren, Garnier-Villarreal, Dowsett, \& Little, 2016). Supports provided by families and teachers are critical to foster and strengthen students' self-awareness about the abilities they have to achieve freely chosen goals. Future studies should then explore ways for families to closely collaborate with schools (Haines, Gross, Blue-Banning, Francis, \& Turnbull, 2015; Lee, Palmer, Turnbull, \& Wehmeyer, 2006) to create consistent opportunities across contexts for youth to build and enhance their personal sense of empowerment. Future work is also needed to consider ways to involve teachers in regular schools to promote self-determination for all students, particularly in Spanish context, where both self-determination research (e.g., Gómez-Vela, Verdugo, González, Badia, \& Wehmeyer, 2012) and assessment (e.g., Verdugo, Vicente, FernándezPulido, Gómez-Vela, Wehmeyer, \& Guillén, 2015) have been primarily centered in students with intellectual disability, and in special education schools (e.g., Arellano, \& Peralta, 2013).

\section{Conclusions}

To close, this study has contributed with empirical knowledge on the variables that must be considered when planning for self-determination instruction. Environmental opportunities provide a foundation for building the essential characteristics of selfdetermined actions (Cavendish, 2016; Shogren et al., 2008), stressing the need to build educational environments where opportunities to learn self-determination skills are provided to all students (Shogren et al., in press). Within MTSS frameworks, Tier 1 supports are universally and preventively designed to offer opportunities for learning to all students. The promotion of self-determination is for all students at Tier 1 (Shogren et al., in press); 
however, if self-determination is to be embedded in MTSS models in inclusive settings, further work is needed to examine how to promote opportunities for self-determination at school for all students in inclusive settings to address differences in self-determination. As an example, the Self-Determined Learning Model of Instruction (Mithaug, Wehmeyer, Agran, Martin, \& Palmer, 1998) stands out as an effective tool (Wehmeyer et al., 2012) that could be used at the Tier 1 level to organize instruction to enable all students to plan steps towards reaching an academic goal, through a problem solving process, which is emphasized in the general curriculum (Shogren et al., in press).

This is particularly important given the finding that students without disabilities surprisingly reported having fewer opportunities at school to develop self-determined actions, suggesting that perhaps because of the emphasis on self-determination on the disability field, greater opportunities are being provided for students with intellectual disability, particularly in segregated schools. Though efforts are being made in fostering universal educational settings for all students in Catalonia (Duran, Giné, \& Marchesi, 2010), special education schools remain the placement where the most of secondary students with intellectual disability are enrolled in (64\%; Ministerio de Educación, Cultura y Deporte, 2015). Inclusive secondary settings are still developing supports for students, including students with and without disabilities, to participate and progress in the curriculum, and in self-determination instruction, based on their unique learning needs (Echeita et al., 2009). Research in the Catalan context has pointed out that special schools must start to change, stressing that they may serve as supports for regular schools, providing them with their knowledge, experience and resources to build educational settings for all students to reach their personal outcomes (Font-Roura et al., 2013). Then, in Catalonia, Spain, and in all countries, efforts are needed to determine not only where students with intellectual disability learn, but how to effectively support them in inclusive contexts to develop critical skills, such as self-determination 
(Ayres, Lowrey, Douglas, \& Sievers, 2011; Font-Roura, \& Giné, 2016; Shogren, McCart, Lyon, \& Sailor, 2015).

\section{References}

Arellano, A., \& Peralta, F. (2013). Self-determination of young children with intellectual disability: understanding parents' perspectives. British Journal of Special Education, 40(4), 176-181. doi: 10.1111/1467-8578.12037

Ayres, K. M., Lowrey, K. A., Douglas, K. H., \& Sievers, C. (2011). I Can identify Saturn but I Can't Brush My Teeth: What happens When the Curricular Focus for Students with Severe Disabilities Shifts. Education and Training in Autism and Developmental Disabilities, 46(1), 11-21.

Carter, E. W., Lane, K. L., Cooney, M., Weir, K., Moss, C. K., \& Machalicek, W. (2013). Self-Determination Among Transition-Age Youth With Autism or Intellectual Disability: Parent Perspectives. Research \& Practice for Persons with Severe Disabilities, 38(3), 129-138.

Carter, E. W., Owens, L., Trainor, A. A., Sun, Y., \& Swedeen, B. (2009). Self-determination skills and opportunities of adolescents with severe intellectual and developmental disabilities. American Journal of Intellectual and Developmental Disabilities, 114(3), 179-192.

Cavendish, W. (2016). The Role of Gender, Race/Ethnicity, and Disability Status on the Relationship Between Student Perceptions of School and Family Support and Selfdetermination. Career Development and Transition for Exceptional Individuals, 39(2).

Duran, D., Giné, C., \& Marchesi, A. (2010). Guia per a l'anàlisi, la reflexió i la valoració de pràctiques inclusives. Generalitat de Catalunya, department d'Educació. Barcelona. 
Echeita, G., Simón, C., Verdugo, M. A., Sandoval, M., López, M., Calvo, I., \& Gónzalez-Gil, F. (2009). Paradojas y dilemas en el proceso de inclusion educativa en España. Revista de Educación, 349, 153-178.

Font-Roura, J., \& Giné, C. (2016). Educació especial: Una passa endavant. Reptes: Revista d'Educació Especial, 1(1).

Font-Roura, J., Simó-Pinatella, D., Alomar-Kurz, E., Giné, C., Adam-Alcocer, A. L., Dalmau, M., González-Raventós, M., Pro, M., \& Mas. J. M. (2013). El Rol de los Centros de Educación Especial en Cataluña: Perspectivas de Futuro. Siglo Cero, 44(1), $34-54$.

Gómez-Vela, M., Verdugo, M. A., González-Gil, F., Badia, M., \& Wehmeyer, M. L. (2012). Assessment of the Self-Determination of Spanish Students with Intellectual Disabilities and other Educational Needs. Education and Training in Autism and Developmental Disabilities, 47(1), 48-57.

Guàrdia-Olmos, J., Fuente, E., \& Lozano, L. M. (2008). Bayesian inference for binomial populations. Bayesian estimation for child depression prevalence. Advances and Applications in Statistics, 9(1), 13-35.

Haines, S. J., Gross, J. M. S., Blue-Banning, M., Francis, G. L., \& Turnbull, A. P. (2015). Fostering Family-School and Community-School Partnership in Inclusive Schools: Using Practice as a Guide. Research and Practice for Persons with Severe Disabilities, 40(3), 227-239. DOI: 10.1177/1540796915594141

Lee, S-H., Palmer, S. B., Turnbull, A. P., \& Wehmeyer, M. L. (2006). A Model for ParentTeacher Collaboration to promote Self-determination in Young Children with Disabilities. Teaching Exceptional Children, 38(3), 36-41.

Lee, Y., Wehmeyer, M. L., Palmer, S. B., Williams-Diehm, K., Davies, D. K., \& Stock, S. E. (2012). Examining Individual and Instruction-Related Predictors of the Self- 
Determination of Students With Disabilities: Multiple Regression Analyses. Remedial and Special Education, 33(3), 150-161. doi: 10.1177/0741932510392053

Mason, C., Field, S., \& Sawilowsky, S. (2004). Implementation of self-determination activities and student participation in IEPs. Exceptional Children, 70, 441-451.

McGuire, J. \& McDonnell, J. (2008). Relationships Between Recreation and Levels of SelfDetermination for Adolescents and Young Adults With Disabilities. Career Development for Exceptional Individuals, 31(3), 154-163. doi:

$10.1177 / 0885728808315333$

Mithaug, D. E., Mithaug, D. K., Agran, M., Martin, J. E., \& Wehmeyer, M. L. (Eds.). (2003). Self-determined learning theory: Construction, verification, and evaluation. Mahwah, NJ: Lawrence Erlbaum Associates, Publishers.

Mithaug, D. E., Wehmeyer, M. L., Agran, M., Martin J., \& Palmer, S. B. (1998) The selfdetermined learning model of instruction: Engaging students to solve their learning problems. In M. L. Wehmeyer \& D. J. Sands (Eds.) Making it happen: Student involvement in educational planning, decision-making and instruction (pp. 299-328). Baltimore: Paul H. Brookes Publishers.

Ministerio de Educación, Cultura y Deporte. (2015). Enseñanzas no universitarias. Alumnado con necesidad específica de apoyo educativo. Curso 2013-2014. Retrieved from: http://www.mecd.gob.es/servicios-al-ciudadano-mecd/estadisticas/educacion/nouniversitaria/alumnado/Necesidades-de-apoyo/Curso-2013-14.html

Morningstar, M. E., Lombardi, A., Fowler, C. H., \& Test, D. W. (2015). A College and Career Readiness Framework for Secondary Students with Disabilities. Career Development and Transition for Exceptional Individuals, 1-13. doi:10.1177/2165143415589926. 
Mumbardó-Adam, C., Guàrdia-Olmos, J., Adam-Alcocer, A., Carbó-Carreté, M., BalcellsBalcells, A., Giné, C., \& Shogren, K. A. (2016). Self-determination and Intellectual Disability Classification. A meta-analytic study. Manuscript submitted for publication.

Nota, L., Ferrari, L., Soresi, S., \& Wehmeyer, M. (2007). Self-Determination, social abilities and the quality of life of people with intellectual disability. Journal of Intellectual Disability Research, 51, 850-865. doi:10.1111/j.1365-2788.2006.00939.

Nota, L., Ferrari, L., Soresi, S., \& Wehmeyer, M. (2011). A Multivariate analysis of the selfdetermination of adolescents. Journal of Happiness Studies, 12, 245-26. DOI 10.1007/s10902-010-9191-0

Palmer, S. B., Wehmeyer, M. L., \& Shogren, K. A. (2016). The development of selfdetermination. In M.L. Wehmeyer, KA. Shogren, T. Little, \& S. Lopez (Eds.), Handbook on the development of self-determination. New York: Springer.

Palmer, S. B., \& Wehmeyer, M. L. (2003). Promoting self-determination in early elementary school: Teaching self-regulated problem-solving and goal-setting skills. Remedial and Special Education, 24(2), 115-126.

Pierson, M. R., Carter, E. W., Lane, K. L., \& Glaeser, B. C. (2008). Factors influencing the self-determination of transition-age youth with high-incidence disabilities. Career Development for Exceptional Individuals, 31(2), 115-125.

Shogren, K. A. (2013). A social-ecological analysis of the self-determination literature. Intellectual and Developmental Disabilities, 51, 496-511. doi: 10.1352/1934-955651.6.496. doi: 10.1352/1934-9556-51.6.496.

Shogren, K. A., Garnier-Villarreal, M., Dowsett, C., \& Little, T. D. (2016). Exploring Student, Family and School Predictors of Self-determination using NLTS2 Data. Career Development and Transition for Exceptional Individuals, 39(1), 23-33. 
Shogren, K. A., Kennedy, W. K., Dowsett, C., Garnier-Villarreal, M., \& Little, T. D. (2012). Exploring Essential Characteristics of Self-Determination for Diverse Students Using data from NLTS2. Career Development and Transition for Exceptional Individuals, 39, 23-33. doi: $10.1177 / 2165143413486927$

Shogren, K. A., Lopez, S. J., Wehmeyer, M. L., Little, T. D., \& Pressgrove, C. L. (2006). The role of positive psychology constructs in predicting life satisfaction in adolescents with and without cognitive disabilities. An exploratory study. The Journal of Positive Psychology, 1, $37-52$.

Shogren, K. A., Luckasson, R., \& Schalock, R. L. (2014). The definition of "context" and its application in the field of intellectual disability. Journal of Policy and practice in Intellectual Disabilities, 11(2), 109-116. doi: 10.1352/1934-9556-51.2.132.

Shogren, K. A., McCart, A. B., Lyon, K. J., \& Sailor, W. S. (2015). All Means All: Building Knowledge for Inclusive Schoolwide Transformation. Research and Practice for Persons with Severe Disabilities, 40(3), 173-191. doi: 10.1177/1540796915586191

Shogren, K. A., Wehmeyer, M. L., \& Lane, K. L. (in press). Embedding Interventions to Promote Self-determination within Multi-Tiered Systems of Supports. Exceptionality.

Shogren, K. A., Wehmeyer, M. L., Little, T. D., Forber-Pratt, A. J., Palmer, S. B., \& Seo, H. (2015). Preliminary validity and reliability of scores on the Self-Determination Inventory-Student Report Version. Career for Development and Transition for Exceptional Individuals, 50(3), 251-263. doi: 10.1177/2165143415594335

Shogren, K. A., Wehmeyer, M. L., Palmer, S. B., Forber-Pratt, A. J., Little, T. J., \& Lopez, S. (2015). Causal agency theory: reconceptualizing a functional model of selfdetermination. Education and training in autism and developmental disabilities, 50(3), 251-263. 
Shogren, K. A., Wehmeyer, M. L., Palmer, S. B., \& Paek, Y. (2013). Exploring Personal and School Environment Characteristics that Predict Self-Determination. Exceptionality: A Special Education Journal, 21(3), 147-157. doi: 10.1080/09362835.2013.802231

Shogren, K. A., Wehmeyer, M. L., Palmer, S. B., Rifenbark, G. G., \& Little, T. D. (2015). Relationships between self-determination and postschool outcomes for youth with disabilities. Journal of Special Education, 53, 30-41. doi:10.1177/0022466913489733

Shogren, K. A., Wehmeyer, M. L., Palmer, S. B., Soukup, J. H., Little, T. D., Garner, N., \& Lawrence, M. (2007). Examining Individual and Ecological Predictors of the SelfDetermination of Students With Disabilities. Council of Exceptional Children, 73(4), 488-509.

Shogren, K. A., Wehmeyer, M. L., Palmer, S. B., Soukup, J. H., Little, T. D., Garner, N., \& Lawrence, M. (2008). Understanding the construct of self-determination: Examining the relationship between The Arc's Self-Determination Scale and the American Institute for Research Self-Determination Scale. Assessment for Effective Instruction, 33, 94-107.

Test, D. W., Mazzotti, V. L., Mustian, A. L., Fowler, C. H., Kortering, L., \& Kohler, P. (2009). Evidence-Based Secondary Transition Predictors for Improving Postschool Outcomes for Students with Disabilities. Career Development for Exceptional Individuals, 32(3), 160-181.

Vicente, E., Verdugo, M. A., Gómez-Vela, M., Fernández-Pulido, R., Wehmeyer, M. L., \& Guillén, V. M. (in press). Personal characteristics and school contextual variables associated with student self-determination. Journal of Policy and Practices in Intellectual Disability.

Verdugo, M. A., Vicente, E., Fernández-Pulido, R., Gómez-Vela, M., Wehmeyer, M. L., \& Guillén, V. (2015). A psychometric evaluation of the ARC-INICO Self-Determination 
Scale for adolescents with intellectual disabilities. International Journal of Clinical and Health Psychology, 15, 149-159.

Wehmeyer, M. L. (1992). Self-determination and the education of students with mental retardation. Education and Training in Mental Retardation, 27, 302 - 314.

Wehmeyer, M. L. \& Garner, N. W. (2003). The Impact of Personal Characteristics of People with Intellectual and Developmental Disability on Self-Determination and Autonomous Functioning. Journal of Applied Research in Intellectual Disabilities, 16, 255-265.

Wehmeyer, M. L. \& Kelchner, K. (1995). The Arc's Self-Determination Scale. Arlington, TX: The Arc National Headquarters.

Wehmeyer, M. L., Kelchner, K., \& Richards, S. (1996). Essential characteristics of selfdetermined behavior of individuals with mental retardation. American Journal on Mental Retardation, 100, $632-642$.

Wehmeyer, M. L., Shogren, K. A., Palmer, S. B., Williams-Diehm, K. L., Little, T. D., \& Boulton, A. (2012). The Impact of the Self-Determined Learning Model of Instruction on Student Self-Determination. Exceptional Children, 78(2), 135-153.

Wolman, J. M., Campeau, P. L., DuBois, P. A., Mithaug, D. E., \& Stolarski, V. S. (1994). Air Self-Determination Scale and User Guide. Columbia: American Institutes for Research. 
Table 1

Predictors of essential characteristics of self-determination

Model $\quad \chi^{2}$ Likelihood-ratio Coefficients $d f$

Volitional actions

Opportunities at Home

$29.223^{*}$

15

Opportunities at School

21.841

16

Intellectual Disability

$37.091 * *$

1

Gender

.234

1

Age

14.021

9

Agentic actions

Opportunities at Home

15.685

15

Opportunities at School

15.685

16

Intellectual Disability

$36.796^{* *}$

1

Gender

.801

1

Age

$19.942 *$

9

Action-control beliefs

Opportunities at Home

$65.872 * *$

15

Opportunities at School

$28.659 *$

16

Intellectual Disability

$24.057 * *$

1

Gender

2.845

1

Age

$22.609 * *$

9

Note: $* p<.05, * * p<.01$ 
Table 2

Predictors of self-reported Capacities

\begin{tabular}{|c|c|c|}
\hline Model & $\chi^{2}$ Likelihood-ratio Coefficients & $d f$ \\
\hline Opportunities at Home & $61.233 * *$ & 15 \\
\hline Opportunities at School & $45.731 * *$ & 16 \\
\hline Intellectual Disability & 4.583 & 1 \\
\hline Gender & 3.415 & 1 \\
\hline Age & $27.025 * *$ & 9 \\
\hline
\end{tabular}

Note: $* p<.05, * * p<.01$ 